\title{
A CARACTERIZAÇÃO DE PROFESSORES FORMADORES EM UBERABA: ELEMENTOS PARA A PROFISSIONALIDADE E IDENTIDADE DOCENTE
}

\author{
THE DESCRIPTION OF TEACHERS TRAINERS IN UBERABA: ELEMENTS FOR \\ PROFESSIONALISM AND TEACHER IDENTITY
}

\author{
Diego Carlos Pereira ${ }^{1}$
}

\begin{abstract}
RESUMO
Este trabalho insere-se nas problemáticas da profissionalidade e identidade dos professores que atuam em cursos de licenciatura presenciais em Uberaba-MG. O objetivo central deste texto é apresentar e discutir uma caracterização destes professores formadores suscitando elementos e atributos que constituem a profissionalidade e a identidade destes docentes. A metodologia empregada é de natureza qualitativa e, para este texto, utilizamos dados oriundos de questionários mistos respondidos por professores formadores da cidade, sendo esta, uma etapa inicial do estudo. Com os dados percebemos que a atribuição de pertencimento à profissão docente dos sujeitos pesquisados representam uma problemática instigante, visto que, muitos não se identificam como licenciados. Problematizamos que os professores formadores em Uberaba possuem uma relação identitária (re)construída com o lugar já que mudaram pelas questões profissionais. Também inferimos que a formação continuada desses professores e sua atuação profissional no trabalho docente representam desafios para o ensino superior.
\end{abstract}

PAlAVRAS-CHAVE: Formação de Professores. Docência no Ensino Superior. Profissionalidade Docente. Identidade docente.

\begin{abstract}
This article is part of the problem of identity and professionalism of professors who works in teachers training undergraduate courses in Uberaba's city, Brazil. The main objective of this paper is to present and discuss a characterization of these teacher's trainers raising elements and attributes that make up the professionalism and the identity of these professors. The methodology is qualitative and, for this text, we use data from mixed questionnaires by teacher's trainers of the city, which is an initial stage of the study. With the data we see that the assignment of belonging to the teaching profession of the individuals represent a compelling problem, since many do not identify themselves as professor in teacher's training undergraduate courses. We problematize the teacher's trainers in Uberaba have a relationship of identity (re)constructed with the place since changed the professional issues. Also we infer that the continued training of these professors and their professional practice in teaching pose challenges for higher education.
\end{abstract}

KEYWORDS: Teacher Education Training; Teaching in Higher Education; Teacher Professionalism; teacher identity;

\section{INTRODUÇÃO}

Este trabalho projeta-se no âmbito das problemáticas que discutem a formação de professores no ensino superior, em especial, a constituição da profissionalidade e da

\footnotetext{
${ }^{1}$ Mestre em Educação pela Universidade Federal do Triângulo Mineiro - UFTM. Email: diego-carlinho@hotmail.com

Projeto financiado pela Fapemig - Processo APQ-03414-12
} 
identidade de professores que atuam em cursos de licenciatura ofertados na modalidade presencial em duas instituições públicas da cidade de Uberaba/MG.

Com isso, o objetivo central deste texto é apresentar e discutir uma caracterização de professores formadores que atuam em cursos presenciais de licenciatura em Uberaba-MG, suscitando elementos e atributos que constituem a profissionalidade e a identidade destes docentes.

Salientamos que este trabalho configura-se como considerações de uma etapa inicial de uma pesquisa de mestrado que ainda está em desenvolvimento. Portanto, nossos objetivos e considerações aqui são restritos em comparação com o estudo como um todo. Portanto, não temos pretensões de estabelecer dados conclusivos ou fechados, mas sim de apresentar as nossas primeiras reflexões a partir da primeira etapa do estudo e, com isso, contribuir para as discussões acadêmicas sobe a formação de professores.

Acreditamos ainda que trabalhos e pesquisas que versam sobre essa temática contribuem para a formação de professores como um todo por considerar elementos pessoais dos sujeitos e, assim, consideramos que "o professor é uma pessoa e uma parte importante da pessoa é o professor" (Nias Jeniffer, apud Nóvoa, 1999, p.15). Neste sentido, nos inquietamos com estes elementos que caracterizam os professores formadores à medida que os mesmos fazem parte do processo de formação de professores para a educação básica na cidade.

\section{Referenciais teóricos}

Esta pesquisa possui como pressupostos básicos a fundamentação teórica acerca da profissionalidade docente e da identidade docente. Acreditamos que nossas reflexões neste texto não simbolizam traços ou conclusões definitivas do estudo, mas suscitam alguns elementos para a discussão da profissionalidade e da identidade dos professores formadores em cursos de licenciatura.

Contextualizando a profissão docente Bourdoncle (1991) busca organizar a perspectiva teórica acerca da constituição profissional da docência e delineia três dimensões de sua análise: a profissionalidade, o profissionismo e o profissionalismo. $\mathrm{O}$ autor entende que a profissionalidade está relacionada com o conjunto de conhecimentos e capacidades socialmente colocados como expectativa profissional, sendo marcos de referência para a sua ação profissional. 
O profissionismo, segunda dimensão citada pelo autor, relaciona-se com um habitus coletivo construído a partir de estratégias e retóricas coletivas representadas socialmente por aquele grupo de profissionais. Já o profissionalismo está relacionado com a adesão pessoal à profissão, a escolha que o profissional faz para a própria vida e constrói sentidos e significados para a mesma (BOURDONCLE, 1991).

Em síntese, para Bourdoncle (1991) a profissionalidade possui como fator decisivo as escolhas pessoais dos sujeitos e a forma como elas se articulam culturalmente em suas trajetórias e em seu contexto institucional, ou seja, à sua identidade profissional e está em constante construção.

Em nossa pesquisa, a profissionalidade emerge como foco de nossas preocupações sobre a profissão docente, pois, nossa inquietação parte dos sujeitos e os significados que os mesmos atribuem à sua atuação, portanto, à(s) maneira(s) e característica(s) de identificação profissional que os professores formadores enfatizam em suas experiências e posições pessoais ao longo do exercício profissional.

Diante deste parâmetro de intensas transformações que envolvem o magistério superior, a discussão acerca da profissionalidade docente pressupõe contextualizá-la de acordo com a configuração dos elementos históricos, sociais e culturais em que vivem os sujeitos bem como em que se situa a realidade a ser investigada, portanto, a profissionalidade assume complexidade por não ser estática (ROLDÃO, 2005). Desse modo, a caracterização a que nos propomos aqui, como parte de uma pesquisa maior, justifica-se pelo ponto de vista dos elementos sociais que contextualizam os sujeitos.

Para Roldão (2005), a profissionalidade se configura como um conjunto não uniforme de elementos e/ou fatores que permitem compreensões da profissão. Para a autora entre os aspectos mais comuns para os pesquisadores que estudam a profissionalidade estão: a especificidade da função (o reconhecimento social associado à atividade); os saberes específicos (conjunto de técnicas e conhecimentos que fundamentam sua atividade); o poder de decisão (o controle e autonomia de sua atividade com consequente responsabilização social); e a pertença a um corpo coletivo (que defende, organiza e regula o exercício da função e legitima politicamente os seus saberes).

Neste sentido, a profissionalidade baseia-se por uma aliança entre a teoria e a prática construída por sua experiência e agregada de valores coletivos e individuais que compõem sua identidade, sendo assim, segundo Pimenta e Anastasiou (2005), uma contribuição para a profissionalização docente. 
Para Pimenta (2005) a identidade profissional se constrói a partir da significação social da profissão, da revisão dos significados e das tradições, reafirmação de práticas valorizadas culturalmente do confronto entre as teorias e práticas, da investigação das práticas, construindo novas teorias. Constrói-se pelo significado que o professor atribui à atividade docente a partir de seu modo de vida, representações e contextualização social, e das relações com outros professores nas diferentes instituições.

Dubar (2005) desenvolve os pressupostos sobre a questão da identidade a partir da "forma identitária". As formas identitárias profissionais se constituem a partir das relações sociais e de trabalho que se configuram na realidade dos sujeitos. As pesquisas deste autor, realizadas por décadas, elucidam os processos de socialização pelos quais as identidades profissionais se constroem e se reconstroem ao longo da vida.

Para Dubar (2005, p.136) a identidade é “[...] resultado a um só tempo estável e provisório, individual e coletivo, subjetivo e objetivo, que, conjuntamente, constroem os indivíduos e definem as instituições”. Neste sentido, a constituição da identidade é um aspecto complexo que insere-se no campo da formação de professores sob diversos aspectos individuais coletivos que constroem estruturas organizacionais e perpassam a constituição do sujeito.

Para compreendermos a estruturação identitária é preciso retomar a articulação dos processos identitários que se desenvolvem nas múltiplas relações na vida e no cotidiano, que são heterogêneos, inseparáveis, complementares ou contraditórios. Nessa dinâmica consideram-se os processos biográficos - identidade para si (o que o indivíduo diz de si mesmo, o que pensa ser, ou gostaria de ser), e os processos relacionais - identidade para outro (quem o outro diz que eu sou, a identidade que o outro me atribui). Na articulação desses processos ocorre a atribuição de papéis pelo outro, a interiorização que é a aceitação e vivência do papel e a incorporação, processo pelo qual esse papel passa a fazer parte da identidade social-profissional do indivíduo (DUBAR, 2005).

Dando continuidade às explanações do autor, consideramos a identidade com um processo de construção subjetiva do sujeito historicamente situado, e por isso, não é um dado imutável. Para Pimenta (2009) a identidade é legitimada e também transformada em determinado contexto e momento histórico, respondendo às necessidades que estão postas pelas sociedades.

Para a autora a identidade do professor está relacionada à significação social da profissão, da revisão das tradições. Isso implica em suas práticas, no confronto com as teorias 
que se distanciam da realidade escolar com as praticas consagradas culturalmente e que permanecem significativas no cotidiano escolar.

Ainda segundo a autora, as práticas também se constroem pelo significado que cada professor, enquanto ator e autor, confere à atividade docente nas experiências de seu cotidiano a partir de seus valores, de seu modo de situar-se no mundo, de sua história de vida, de suas representações sociais, de seus saberes, de suas angústias e anseios, do sentido que tem em sua vida o "ser professor" (PIMENTA, 2009).

Neste sentido, a constituição identitária dos professores formadores que atuam nos cursos de licenciatura perpassa diversos aspectos que estamos estudando em sentido amplo no estudo envolvido, no entanto, para este trabalho, daremos enfoque à caracterização desses docentes e, a partir de nossas interpretações, elencar alguns aspectos, do ponto de vista pessoal e profissional, da constituição da identidade e da profissionalidade dos sujeitos.

\section{Aspectos Metodológicos}

Esse trabalho parte de uma pesquisa de natureza qualitativa. A perspectiva qualitativa deste estudo fundamenta-se em Ludke e André (2008) que afirmam que se pressupõe a perspectiva dos sujeitos sobre os processos sociais, econômicos, culturais e educacionais em que os mesmos estão inseridos. Com isso, são elementos da pesquisa qualitativa os significados e experiências construídas pelos sujeitos no seu cotidiano, contextualizadas pelo processo a ser investigado.

Como salientamos anteriormente, este trabalho configura-se como uma parte inicial de uma pesquisa de mestrado ainda em desenvolvimento. Esta pesquisa procura discutir a profissionalidade docente nos cursos de licenciatura e, para caracterização geral dos docentes utilizou-se de questionários.

Contudo, a primeira fase do estudo da qual debruçaremos nossas análises é constituída de questionários mistos, conforme propõe Fiorentini e Lorenzato (2006). Buscamos realizar uma caracterização e descrição do dos sujeitos do estudo, explicitando questões inerentes aos dados referentes à profissionalidade e formação destes docentes. Ainda no que tange aos pressupostos apontados pelos autores, realizamos um questionário misto, que intercala questões de interesse quantitativo (fechadas) com questões abertas que ampliam o leque de dados qualitativos à pesquisa. Assim, conforme os pressupostos dos autores, 
mesmo lançando mão de dados quantitativos, nossa perspectiva aqui é de discuti-los qualitativamente.

\section{Discussões e interpretações dos dados}

Diante da nossa problemática de pesquisa e das condições geográficas do Programa de Pós-graduação ao qual estamos vinculados, definimos que a realização deste estudo dar-seia nos cursos de Licenciatura oferecidos na modalidade presencial da cidade de Uberaba, Minas Gerais. No caso, apenas duas instituições públicas oferecem estes cursos na cidade, ambas federais, sendo uma Universidade e outra, um Instituto de Educação, Ciência e Tecnologia.

Ambas as instituições oferecem cursos de licenciatura em Química e Ciências Biológicas, já a Universidade oferece ainda Licenciaturas em Matemática, Física, Letras, História e Geografia e Educação no Campo e o Instituto, oferece também a Licenciatura em Ciências Sociais. Segundo os dados fornecidos pela Universidade, seus cursos de licenciatura reúnem 144 docentes entre mestres e doutores e entre efetivos, substitutos e temporários; já no Instituto, seus cursos de licenciatura reúnem 40 docentes.

Realizamos um recorte a partir do currículo lattes dos professores de acordo com os interesses de nossa pesquisa como um todo e, selecionamos o total de 45 docentes, que em seus currículos possuíam bacharelado em sua formação inicial ou especificavam no currículo "graduação em". Salientamos que esta seleção foi feita devido ao objetivo maior da pesquisa de mestrado que busca discutir a profissionalidade dos professores bacharéis que atuam nas licenciaturas, no entanto, essa delimitação quanto aos professores bacharéis não é o nosso foco para este texto.

Diante disso, dos 45 docentes iniciais, 28 responderam ao questionário, sendo 10 via e-mail e 18 via contato pessoal. Acreditamos que, apesar das dificuldades de resposta tivemos uma devolutiva satisfatória e que este processo de contato com os sujeitos do estudo e suas dificuldades é natural em meio aos desafios da pesquisa qualitativa.

Dos 28 professores que responderam o questionário, 8 possuem formação apenas de bacharelado. Sabemos pela pré-seleção nos currículos que esse número é maior, visto que, pelo menos 5 deles não deram a devolutiva do instrumento. Além desses 5 , os quais já sabíamos que são bacharéis ainda tem os outros 10 questionários sem retorno aos quais na pré-seleção indicam a "graduação em". 
Uma questão que nos chamou a atenção é que 6 docentes responderam que possuem apenas a Licenciatura em sua área, no entanto, em seus Currículos Lattes está a "graduação em”. Percebemos que a maioria dos professores que afirmam em seus currículos que possuem “graduação em”,na verdade, é formada em ambas as modalidades. Ora, tanto licenciatura quanto bacharelado são graduações, mas com diferentes processos formativos e finalidades, no entanto, até que ponto esses professores estão dispostos a se identificarem em seus currículos como licenciados? Há alguma restrição destes professores em se identificarem como licenciados mesmo sendo também bacharéis? A nosso ver, há uma problemática quanto à identificação nos currículos do curso de licenciatura, visto que essa atribuição identitária pode estar relacionada a própria identificação do sujeito com a docência ou mesmo um reflexo da estrutura curricular de muitas universidades que ainda formam concomitantemente bacharéis e licenciados ao mesmo tempo.

Outro ponto interessante que percebemos por meio dos questionários é que, majoritariamente, os docentes não são oriundos nem de Uberaba e nem mesmo da região. Apenas um dos docentes que respondeu ao questionário é natural da cidade e outros 8 docentes são de cidades da região do Triângulo Mineiro e Alto Paranaíba. A maioria dos professores (13) é natural do estado de São Paulo e os demais variam entre os estados de Goiás, Paraíba, Paraná e demais regiões de Minas Gerais.

O mesmo se repete quanto às formações destes docentes. Há uma predominância de cursos de graduação realizados no estado de São Paulo (14) e em Minas Gerais (10), sendo apenas um dos professores formados na cidade de Uberaba. Quanto aos cursos de pósgraduação stricto sensu, a concentração é ainda maior quanto aos docentes formados em universidades no estado de São Paulo, sendo 18 na modalidade de mestrado e 21 no doutorado.

Estes dados nos permitem pressupor um contexto de docentes formados predominantemente em universidades renomadas no âmbito da pesquisa acadêmica como Universidade de São Paulo (USP), Universidade Estadual de Campinas (Unicamp) e Universidade Estadual Paulista Júlio Mesquita Filho (Unesp).

Acreditamos que este contexto de formação como característica predominante dos docentes que vêm de fora da cidade deve-se a uma localização geográfica estrategicamente privilegiada de Uberaba próxima ao estado de São Paulo e devido também à constituição apenas recente da Universidade pública na cidade de Uberaba e de seus cursos, o que acarreta 
que ainda não houve tempo hábil para que os professores formados na cidade pudessem atuar na mesma.

Esse contexto de professores oriundos de outras regiões provoca ainda questões subjetivas aos sujeitos, pois a mudança para Uberaba faz com que os professores reconstruam suas identidades na relação com o lugar, com a instituição e com os demais sujeitos, bem como emergem aspectos significativos quanto ao distanciamento da família e amigos de seu lugar de origem e a reconstrução de laços novos afetivos devido a uma relação de trabalho com a docência. Este ponto nos interessa bastante para o desenvolvimento da pesquisa no que tange à construção da identidade social perante a essa ruptura, bem como, a constituição profissional destes docentes que os levaram a essa ruptura com o lugar.

Outro aspecto que abordamos nos questionários foi a formação continuada dos professores, visto que esse processo pode se constituir como uma forma de profissionalização para a docência. Percebemos que, predominantemente, os professores realizam atividades que estão relacionadas com a sua área de conhecimento específica ou áreas correlatas, geralmente articuladas aos seus projetos de pesquisa e extensão desenvolvidos na instituição, bem como, predominantemente, os professores responderam "nunca" ou "quase nunca" para áreas que não abrangem as suas especificidades. A nosso ver, essa questão problematiza a fragmentação desse processo de formação que está relacionada com a estrutura do ensino superior organizado de maneira disciplinar. Ora, onde estão os pressupostos de interdisciplinaridade e transdisciplinaridade nesse processo?

Ainda realizamos uma pergunta específica sobre a formação continuada na área de educação ou ensino e apenas 9 professores responderam que faziam "sempre" ou "muito", destes, 3 possuem apenas a formação de bacharelado. Pensando que os sujeitos são, perante a própria legislação vigente, professores do magistério superior e que a especificidade de sua função relaciona-se ao processo de ensino, encontramos uma problemática quanto às especificidades da profissão docente no ensino superior, visto que a maioria dos docentes participa pouco ou não participa de processos de formação continuada em áreas pedagógicas.

Quanto à atuação dos docentes que responderam ao questionário, predominantemente, só atuam/atuaram em cursos de licenciatura excetuando os professores do Instituto Federal, que são os únicos que atuam/atuaram em cursos técnicos ou de bacharelado concomitantemente. A maioria (23) possui cinco anos ou mais de atuação no magistério sendo que 15 deles possuem dez ou mais anos de atuação como professores, no entanto, predomina o tempo de atuação desses professores no ensino superior privado. A 
metade dos professores bacharéis chegaram a atuar, por menos de 5 anos na educação básica, com exceção de uma professora que atuou por 15 anos.

Sobre o trabalho docente, dois aspectos nos chamaram a atenção: a maioria dos professores (16) afirmou trabalhar em três turnos do dia em suas instituições bem como, 23 professores afirmaram não ter qualquer tipo de acompanhamento pedagógico de seu trabalho. Para nós, estes dados contextualizam algumas questões institucionais que são atreladas ao trabalho docente no ensino superior como a sobrecarga de trabalho bem como à preocupação que as instituições têm dado à docência enquanto espaço de problematização de pesquisa, mas também, da docência.

\section{CONSIDERAÇÕES FINAIS}

Neste trabalho, procuramos apresentar e discutir uma caracterização de professores formadores que atuam em cursos presenciais de licenciatura em Uberaba-MG, suscitando elementos e atributos que constituem a profissionalidade e a identidade destes docentes. Inserido em um projeto amplo de mestrado em vários cursos de licenciatura e com etapas posteriores ainda a serem realizadas, este artigo busca discutir de maneira específica os primeiros resultados do estudo.

Percebemos que a caracterização destes docentes configura-se como uma conjuntura de elementos que pressupõem algumas reflexões e um "perfil" deste professor formador que atua nas licenciaturas presenciais na cidade. Estas características, ao longo das análises, tornaram-se elementos iniciais sobre as estruturas identitárias que fazem parte da trajetória e da vida destes licenciandos e, consequentemente, possuem atribuições em seu processo formativo e em sua constituição de identidade profissional, assim como apontamos nos referenciais de Dubar (2005) e Pimenta (2005).

É importante destacar que esses dados iniciais, apesar de não fornecerem um arcabouço completo de reflexões acerca da identidade e da profisssionalidade desses professores enquanto processos construídos pelos sujeitos, que buscaremos discutir em etapas posteriores do estudo, nos fornecem uma série de elementos sociais sobre os docentes que problematizam sua identidade e sua profissionalidade.

Percebemos que a atribuição de pertencimento à profissão docente dos sujeitos pesquisados representam uma problemática instigante, visto que, muitos não se identificam como licenciados. Vimos que os professores formadores em Uberaba possuem uma relação 
identitária (re)construída com o lugar ao qual tiveram que mudar pelas questões profissionais. Também percebemos que a formação continuada desses professores e sua atuação profissional no trabalho docente representam desafios para o ensino superior.

Reiteramos que estes dados iniciais da pesquisa problematizam ainda mais nosso estudo. Para nós, ao aprofundarmos nessas questões com os professores nas próximas etapas do estudo, buscaremos e confrontaremos a seguinte questão que não conseguiremos responder, mas sim apontar direcionamentos: como se constituem as identidades e a profissionalidade dos professores formadores nos cursos de licenciatura? Quais são os processos de cada sujeito e como se constituem suas trajetórias?

\section{REFERÊNCIAS}

BOURDONCLE, R. La profesionalisation des enseignants: analyses sociologiques anglaises et américaines. Revue Française de Pédagogie. n. 94, 1991.

DUBAR, C. A socialização. Construção das identidades sociais e profissionais. São Paulo: Martins Fontes, 2005.

FIORENTINI, D.; LORENZATO, S. Investigação em Educação Matemática: percursos teóricos e metodológicos. Campinas-SP: Autores Associados, 2006.

LUDKE, Menga; ANDRÉ, Marli Eliza Dalmazo Afonso de. Pesquisa em educação: abordagens qualitativas. São Paulo (SP): EPU, 2008.

NÓVOA, António et al. Profissão professor. 2. ed. Porto: Porto, c1999.

PIMENTA, Selma Garrido. Formação de professores: saberes da docência e identidade do professor. Rev. Fac. Educ. [online]. 1996, v. 22, n.2, p. 72-89.

PIMENTA, S. G. (Org.) Formação de professores: identidade e saberes da docência: In:

Saberes Pedagógicos e atividade docente. 4 ed. São Paulo: Cortez, 2009.

PIMENTA, Selma Garrido; ANASTASIOU, Léa das Graças Camargos. Docência no Ensino Superior. 2 ed. São Paulo: Cortez, 2005.

ROLDÃO, Maria do Céu Neves. Profissionalidade docente em análise: especificidades do ensino superior e não superior. Nuances: estudos sobre educação - ano XI, v. 12, n. 13, jan./dez. 2005.

RECEBIDO EM: 09/03/2016

APROVADO PARA PUBLICAÇÃO EM: 29/11/2016

http://www.uftm.edu.br/revistaeletronica 